\title{
THE EFFECTS OF ICE THICKNESS ON THE EXCHANGE OF SOLAR RADIATION OVER THE POLAR OCEANS*
}

\author{
By Thomas C. Grenfell \\ (Department of Atmospheric Sciences, University of Washington, Seattle, Washington 98195, \\ U.S.A.)
}

\begin{abstract}
Aвstract. Total transmission, absorption, and reflection of solar radiation have been determined for bare blue and white ice between 0.02 and $0.8 \mathrm{~m}$ in thickness as well as for blue ice covered with 0.01 to $0.4 \mathrm{~m}$ of dry packed snow. The calculations were performed at 45 wavelengths between $400 \mathrm{~nm}$ and $2150 \mathrm{~nm}$ using a two-stream model to account for the finite thickness of the ice and snow layers. Total radiative energies were found by numerical integration over wavelength. The results were compared with corresponding calculations for optically thick ice of the same types. Albedos increase from about 0.05 for open water to a maximum of 0.9 for thick snow. For $0.8 \mathrm{~m}$ blue and white ice, predicted albedos on cloudy days are 0.28 and 0.67 respectively. Under clear skies these albedos decrease by to to $30 \%$. Total transmission through thin ice (less than $0.8 \mathrm{~m}$ ) is from $50^{\circ}{ }_{0}$ to $300^{\circ}$ o greater than is predicted by Beer's law depending on ice type and cloud cover. Radiative energy absorption at the surface is independent of thickness, but significant departures from Beer's law of as much as $200 \%$ are evident in all cases below a depth of $2.5 \mathrm{~mm}$. A parameterization scheme is presented for incorporating these results into heat- and mass-
\end{abstract} balance studies.

RÉsumÉ. Les effets de l'épaisseur de la glace sur les échanges de ravonnement solaire dans les Océans polaires. On a déterminé le bilan de la transmission, de l'absorption et de la réflexion du rayonnement solaire pour de la glace nue, bleue et blanche entre 0,02 et $0,8 \mathrm{~m}$ d'épaisseur ainsi que pour la glace bleue recouverte de 0,01 à $0,4 \mathrm{~m}$ de neige sèche tassée. Les calculs ont été conduits pour 45 longueurs d'onde entre $400 \mathrm{~nm}$ et $2150 \mathrm{~nm}$ en utilisant un modèle à deux flux pour tenir compte de l'épaisseur finie des couches de glace et de neige. Les énergies totales de radiation ont été trouvées par interpolation numérique cntre les longueurs d'onde. Les résultats ont été comparés avec les calculs correspondants pour de la glace optiquement épaisse des mêmes types. Les albédos augmentent depuis environ o,05 pour de l'eau libre jusqu'à un maximum de 0,9 pour de la neige épaisse. Pour o,8 $\mathrm{m}$ de glace bleue et blanche, les albédos prévus par temps couvert sont respectivement de 0,28 et 0,67 . Sous ciel clair, ces albédos diminuent de to à $30^{\circ} \%$. La transmission totale à travers une glace mince (moins de $0,8 \mathrm{~m}$ ) est de $50^{\circ}{ }_{\circ}$ à $300^{\circ}{ }_{0}$ supérieure à celle prévue par la loi de Becr selon le type de glace et la nébulosité. L'absorption d'énergie rayonnée à la surface est indépendante de l'épaisseur, mais un écart significatif par rapport à la loi de Beer allant jusqu'à $200^{\circ}{ }_{0}$ est mis en évidence dans tous les cas en dessous d'une profondeur de $2,5 \mathrm{~mm}$. Un schéma de paramétrisation est présenté qui permet d'incorporer ces résultats dans les études de bilans de masse et de bilans thermiques.

Zusammenrassung. Der Einfluss der Eisdicke auf den Austausch der Sonnenstrahlung über den polaren $O$ zeanen. Sowohl für blankes, weisses und blaues Eis mit Dicken zwischen 0,02 und $0,8 \mathrm{~m}$ wie für blaues Eis mit einer 0,01 bis $0,4 \mathrm{~m}$ dicken Decke von trockenem, festem Schnee wurde die gesamte Durchlässigkeit, Absorption und Reflexion der Sonnenstrahlung bestimmt. Die Berechnungen bezogen sich auf 45 Wellenlängen zwischen $400 \mathrm{~nm}$ und $2150 \mathrm{~nm}$ und benutzten ein Zwei-Strom-Modell, um die begrenzte Dicke der Eis- und Schneeschichten berücksichtigen zu können. Die Ergebnisse wurden mit entsprechenden Berechnungen für optisch dickes Eis desselben Typs verglichen. Die Albedowerte wachsen von etwa 0,05 für offenes Wasser bis zu einem Maximum von 0,9 für tiefen Schnee. Die berechneten Albedowerte für $0,8 \mathrm{~m}$ dickes blaues und weisses Eis betragen an wolkigen Tagen 0,28 bzw. 0,67 . Unter klarem Himmel nehmen diese Werte um to bis $30^{\circ}$ ab. Die Gesamtdurchlässigkeit dünnen Eises (weniger als $0,8 \mathrm{~m}$ ) ist um 50 bis $300^{\circ}{ }_{0}$ grösser als nach dem Gesetz von Beer, je nach Eistyp und Wolkendecke. Die Absorption der Strahlungsenergie an der Oberfläche ist unabhängig von der Dicke, aber beträchtliche Abweichungen vom Beer'schen Gesetz, die $200^{\circ}{ }_{0}$ erreichen können, treten in allen Fällen unter einer Tiefe von $2,5 \mathrm{~mm}$ auf. Es wird ein Schema zur Parametrisierung entworfen, das die Aufnahme dieser Ergebnisse in Untersuchungen zum Wärme- und Massenhaushalt erlaubt.

\section{INTRODUCTION}

Understanding the interaction of solar radiation with ice and snow in the polar oceans is fundamental in studies of heat and mass balance at high latitudes. The amount of solar energy absorbed by the ice directly influences not only the rates of melting and freezing at the upper and lower boundaries, but also the thermal and mechanical properties of the ice through internal melting. In addition, the level of primary productivity (photosynthetic

* Contribution 488, Department of Atmospheric Sciences, University of Washington, Seattle, Washington 98195 , U.S.A. 
growth of phytoplankton and algae), which is the ultimate basis for biological activity in the polar regions, depends strongly on the intensity of solar radiation transmitted through the ice.

Of particular importance are the areas of thin ice and open water continually created by differential stresses within the pack, which cause cracking and separation of ice floes. Although such areas comprise only a small fraction of the ice pack, their role in the overall radiative energy budget is substantial. Much of the solar radiation reaching the ocean passes through thin ice because of its low albedo and small optical depth.

Recent field experiments have made available the optical properties as a function of wavelength for first- and multi-year sea ice and for certain types of arctic snow (Grenfell and Maykut, I977). Although these results apply to ice thicker than I $\mathrm{m}$, they can also be used in conjunction with a suitable radiative transfer model to study thinner ice. An important concern is that the optical properties of young growing ice may be quite different from those of more mature ice due to variations in brine volume, crystal structure, and bubble density, which occur mainly in response to changes in temperature as the sea ice ages. Some of these variations, however, may tend to offset one another. For example, young ice has a large brine volume which increases its transparency, but its crystal structure is more complex and finegrained than that of thick ice giving a higher density of scattering surfaces. The relative importance of such effects is not yet known, but the presently available optical properties should provide a reasonable first approximation for cases of thin ice.

A detailed study of the regional energy balance of sea ice involves much more than the radiative energy input alone and is beyond the scope of the present study. The goals of this investigation are: (i) to compare various models for treating radiative transfer in ice; (ii) to investigate the effects of ice thickness, ice type, snow cover, and cloudiness on the reflection, absorption, and transmission of short-wave radiation; and finally (iii) to formulate a simplified parameterization of the radiative transfer problem which can be used efficiently in total energy-balance studies and biological investigations of an ice-covered ocean.

\section{THEORY}

A general theory predicting the transfer of solar radiation through sea ice and snow should satisfy two general criteria. Because spectral extinction coefficients for these materials depend strongly on wavelength (Aschkinass, 1895; Ewan, 1895; Sauberer, 1938; Liljequist, I956; Ockman, I958), the amount of light penetrating to a given depth or back-scattered into the atmosphere can change drastically with wavelength over the solar spectrum. Consequently, the theory should explicitly describe the radiation field as a function of wavelength. At some wavelengths the optical thickness of a floating ice cover is not large even for thicker $(\mathrm{I}-3 \mathrm{~m})$ ice, thus the theory should account for the effects of the discontinuity in scattering at the icewater interface. Since the polar oceans are typically covered by low stratus clouds during the summer, the radiation incident upon the ice is usually diffuse. Under these conditions the radiative transfer can be described adequately by a two-stream approximation which has a convenient analytical solution. This is especially desirable since computations can then be carried out efficiently for the large wavelength set necessary to cover the solar spectrum.

In treating the problem of thin ice, two distinct types are considered. Sea ice with a thickness of $\mathrm{I} \mathrm{m}$ or less is most common and consists mainly of young, rapidly growing ice which has a high salinity. Such ice is homogeneous throughout and is usually covered by dry windpacked snow. For convenience young growing ice is referred to here as blue ice. The second type, white ice, consists of a highly scattering, granular surface layer above a thin transition zone where the ice becomes consolidated. Below the transition zone the optical properties are constant with depth. Although white ice probably does not constitute a major fraction of the thin ice during most of the year, substantial quantities can be produced by summer ablation of 
first-year ice in the marginal ice zones. Since the granular layer does not develop until the snow melts, only bare white ice need be considered.

Consequently, a three-layer radiative transfer model can be used to represent the radiation field in the snow, ice, and water. The theory employed is an adaptation of Schuster's (1905) method as modified by Dunkle and Bevans (1956). It describes the spatial dependence of the down- and up-welling irradiance which are defined as the total radiative energies incident per unit area per second on a horizontal surface from the upper and lower hemispheres respectively. In addition, irradiances with the argument $\lambda$ are defined per unit wavelength. Plane parallel geometry is assumed where the snow and ice layers have thicknesses $h_{\mathrm{s}}$ and $h_{\mathrm{i}}$ respectively.

Specular reflection at the upper surface $\left(R_{\lambda}\right)$ is included explicitly since it is important for thin-ice cases. The down-welling irradiance in the snow or ice at the surface, $F \downarrow_{s, \mathrm{i}}(0, \lambda)$, then equals the fraction of the incident irradiance entering the ice plus the fraction of the up-welling irradiance reflected downwards by the snow-air interface. For snow-covered ice

$$
F \downarrow_{\mathrm{s}}(\mathrm{o}, \lambda)=\left(\mathrm{I}-R_{\lambda}\right) F_{\mathrm{o}}(\lambda)+R_{\lambda} F \uparrow_{\mathrm{s}}(\mathrm{o}, \lambda),
$$

where $F_{0}(\lambda)$ is the incident spectral irradiance, and $F \uparrow_{\mathrm{s}}(\mathrm{o}, \lambda)$ is the up-welling irradiance at the surface. At the snow-ice interface, continuity of the radiation field at each wavelength gives

$$
F \uparrow_{\mathbf{s}}\left(h_{\mathrm{s}}, \lambda\right)=F \uparrow_{\mathbf{i}}\left(h_{\mathrm{s}}, \lambda\right) \quad \text { and } \quad F \downarrow_{\mathrm{s}}\left(h_{\mathrm{s}}, \lambda\right)=F \downarrow_{\mathbf{i}}\left(h_{\mathrm{s}}, \lambda\right) .
$$

Since back-scattering by Arctic ocean water is extremely small (Smith, 1973), up-welling irradiance in the ocean can be neglected, so the boundary condition at the bottom of the ice can be written $F \uparrow_{\mathbf{w}}\left(h_{\mathrm{s}}+h_{\mathrm{i}}, \lambda\right)=0$. A schematic diagram of the model together with the boundary conditions is shown in Figure I. In a given layer the optical properties are specified by the spectral extinction coefficient $\kappa_{\lambda}$ and by the spectral volume reflectivity $r_{\lambda}$. The equations of transfer reported by Dunkle and Bevans (I956) are then used to describe incremental radiation losses due to back-scattering and absorption in infinitesimal layers for both up- and down-welling irradiance. Integration of these equations subject to the above boundary conditions gives the depth dependence of the radiation field taking into account multiple scattering.

Defining $\gamma=\sinh ^{-1}\left(\kappa_{\lambda} / r_{\lambda}\right)$, the solutions can be expressed as follows:

snow:

$$
\left.\begin{array}{l}
F \downarrow_{\mathrm{s}}(h, \lambda)=F_{0}(\lambda) A\left(R_{\lambda}\right) \sinh \left(Q_{\lambda}-\kappa_{\lambda} \mathrm{s} h\right), \\
F \uparrow_{\mathrm{s}}(h, \lambda)=F_{0}(\lambda) A\left(R_{\lambda}\right) \sinh \left(Q_{\lambda}-\gamma_{\mathrm{s}}-\kappa_{\lambda} \mathrm{s} h\right),
\end{array}\right\}
$$

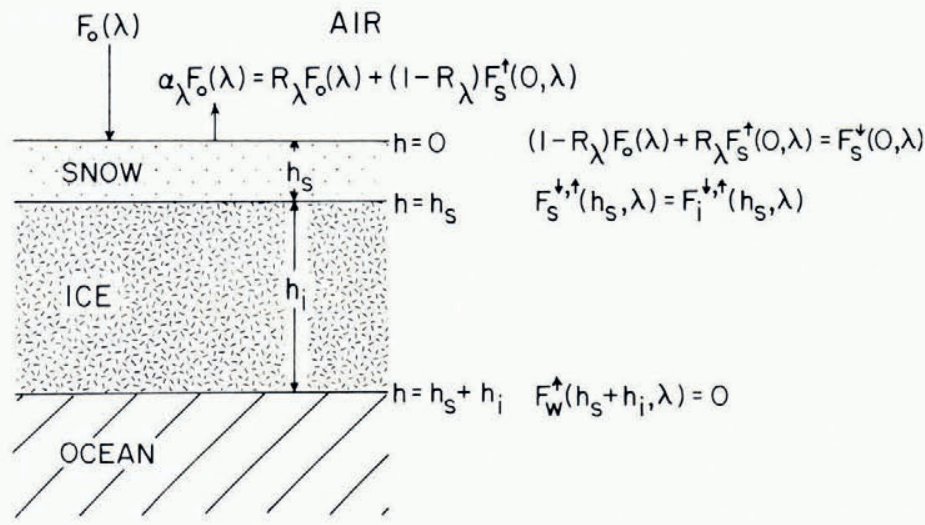

Fig. I. Schematic illustration of the radiative transfer model. 
where

$$
A\left(R_{\lambda}\right)=\left(\mathrm{I}-R_{\lambda}\right) /\left[\sinh Q_{\lambda}-R_{\lambda} \sinh \left(Q_{\lambda}-\gamma_{\mathrm{s}}\right)\right],
$$

and $Q_{\lambda}$ is determined from

ice :

$$
\tanh Q_{\lambda}=\frac{\sinh \left(\kappa_{\lambda}^{\mathrm{s}} h_{\mathrm{s}}+\gamma_{\mathrm{s}}\right) \sinh \left(\kappa_{\lambda}^{\mathrm{i}} h_{\mathbf{i}}+\gamma_{\mathbf{i}}\right)-\sinh \left(\kappa_{\lambda}^{\mathrm{s}} h^{\mathrm{s}}\right) \sinh \left(\kappa_{\lambda}^{\mathrm{i}} h_{\mathbf{i}}\right)}{\cosh \left(\kappa_{\lambda}^{\mathrm{s}} h_{\mathbf{s}}+\gamma_{\mathrm{s}}\right) \sinh \left(\kappa_{\lambda}^{\mathrm{i}} h_{\mathbf{i}}+\gamma_{\mathbf{i}}\right)-\cosh \left(\kappa_{\lambda}^{\mathrm{s}} h_{\mathrm{s}}\right) \sinh \left(\kappa_{\lambda}{ }^{\mathrm{i}} h_{\mathbf{i}}\right)} ;
$$

$$
\begin{aligned}
& F \downarrow_{\mathrm{i}}(h, \lambda)=F_{\mathrm{o}}(\lambda) A\left(R_{\lambda}\right) B_{\lambda} \sinh \left[\kappa_{\lambda}^{\mathrm{i}}\left(h_{\mathrm{s}}+h_{\mathrm{i}}-h\right)+\gamma_{\mathrm{i}}\right], \\
& F \uparrow_{\mathrm{i}}(h, \lambda)=F_{0}(\lambda) A\left(R_{\lambda}\right) B_{\lambda} \sinh \left[\kappa_{\lambda} \mathrm{i}\left(h_{\mathrm{s}}+h_{\mathrm{i}}-h\right)\right],
\end{aligned}
$$

where

$$
B_{\lambda}=\sinh \left[Q_{\lambda}-\kappa_{\lambda} \mathrm{s} h_{\mathrm{s}}\right] / \sinh \left[\kappa_{\lambda}^{\mathrm{i}} h_{\mathrm{i}}+\gamma_{\mathrm{i}}\right]
$$

water:

$$
\begin{aligned}
& F \downarrow_{\mathrm{w}}(h, \lambda)=F_{\mathrm{o}}(\lambda) A\left(R_{\lambda}\right) B_{\lambda}\left(\kappa_{\lambda} \mathrm{i} / r_{\lambda} \mathrm{i}\right) \exp \left[-\kappa_{\lambda} \mathrm{w}\left(h-h_{\mathrm{s}}-h_{\mathrm{i}}\right)\right], \\
& F_{\mathrm{w}}(h, \lambda)=\mathrm{o} .
\end{aligned}
$$

When snow is absent, the solutions reduce to:

and

$$
\left.\begin{array}{l}
F \downarrow_{\mathrm{i}}(h, \lambda)=F_{\mathrm{o}}(\lambda) A^{\prime}\left(R_{\lambda}\right) \sinh \left[\kappa_{\lambda}^{\mathrm{i}}\left(h_{\mathrm{i}}-h\right)+\gamma_{\mathrm{i}}\right], \\
F \uparrow_{\mathrm{i}}(h, \lambda)=F_{0}(\lambda) A^{\prime}\left(R_{\lambda}\right) \sinh \left[\kappa_{\lambda}^{\mathrm{i}}\left(h_{\mathrm{i}}-h\right)\right],
\end{array}\right\}
$$

in the ice, where

$$
A^{\prime}\left(R_{\lambda}\right)=\left(\mathrm{I}-R_{\lambda}\right) /\left[\sinh \left(\kappa_{\lambda}^{\mathrm{i}} h_{\mathrm{i}}+\gamma_{\mathrm{i}}\right)-R_{\lambda} \sinh \left(\kappa_{\lambda}^{\mathrm{i}} h_{\mathrm{i}}\right)\right],
$$

and

$$
\begin{aligned}
& F \downarrow_{\mathrm{w}}(h, \lambda)=F_{\mathrm{o}}(\lambda) A^{\prime}\left(R_{\lambda}\right)\left(\kappa_{\lambda} \mathrm{i} / r_{\lambda} \mathrm{i}\right) \exp \left[-\kappa_{\lambda} \mathbf{w}\left(h-h_{\mathrm{i}}\right)\right], \\
& F \uparrow_{\mathrm{w}}(h, \lambda)=\mathrm{o},
\end{aligned}
$$

in the ocean. The albedo is expressed as

$$
\alpha_{\lambda}=R_{\lambda}+\frac{\left(\mathrm{I}-R_{\lambda}\right) F \uparrow_{l}(\mathrm{o}, \lambda)}{F_{0}(\lambda)},
$$

where $F \uparrow_{l}(\mathrm{o}, \lambda)$ is the up-welling irradiance at the surface. The rate at which radiative energy per unit area $E$ is absorbed by the ice depends on the depth dependence of the net irradiance, $F_{\text {net }}(h, \lambda)=F \downarrow(h, \lambda)-F \uparrow(h, \lambda)$. At a particular depth,

$$
\left(\frac{\hat{\partial} E}{\hat{c} t}\right)_{h}=-\frac{\hat{\imath}}{\hat{\imath} z} \int F_{\text {net }}(h, \lambda) \mathrm{d} \lambda .
$$

In the limit of very large optical depth $\tau_{\lambda}$, where $\tau_{\lambda}=\kappa_{\lambda}\left(h_{\mathrm{s}}+h_{\mathrm{i}}\right)$, the resulting solution of the two-stream model is an exponential law. For a single homogeneous layer

$$
F_{\text {net }}(\lambda, h)=\left(\mathbf{I}-\alpha_{\lambda}\right) F_{0}(\lambda) \exp \left(-\kappa_{\lambda} h\right) \text {. }
$$

This is often called Beer's law and is frequently used to described the radiation field in ice and snow. For young ice, however, large optical depth is a poor approximation in the visible and near infrared, and Beer's law gives a substantial underestimate of the transmitted energy. In addition, Beer's law cannot predict the dependence of albedo on ice thickness. The importance of these limitations will be examined in the results section.

\section{Input parameters}

To specify the solutions to the equations of transfer for a particular type of snow or ice, the appropriate set of optical properties is required. Although the values for blue ice are not known precisely, they are assumed to be similar to those reported by Grenfell and Maykut (1977) for melting first-year blue ice because both types have a high brine volume without a 
distinct surface-scattering layer. Values of $\kappa_{\lambda}$ and $\alpha_{\lambda}$ for thick layers of blue ice, white ice, and dry packed snow in the visible and near infrared can then be taken from Grenfell and Maykut (1977). Since the extinction coefficients are not available beyond $750 \mathrm{~nm}$, they have been estimated by extrapolation based on data for clear ice (Sauberer, 1938; Ockman, 1958). The slope of $\kappa_{\lambda}$ versus wavelength for snow from 600 to $750 \mathrm{~nm}$ agrees with $\kappa_{\lambda}$ being proportional to the square root of the extinction coefficient of clear ice (Bohren and Barkstrom, I974) so $\kappa$ is extrapolated into the infrared on this basis. Since the corresponding relationship for sea ice is not known, infrared values are estimated by extrapolating the $\kappa_{\lambda}$ curves smoothly out to $\mathrm{I} 000 \mathrm{~nm}$. Beyond $\mathrm{I}$ ooo $\mathrm{nm}$ the wavelength dependence of $\kappa_{\lambda}$ for sea ice is assumed to be proportional to that of snow. In all cases the curves are truncated at $10^{4} \mathrm{~m}^{-1}$ since larger values affect the results only in the uppermost $0.1 \mathrm{~mm}$.

For Arctic Ocean water, Smith (1973) found an extinction coefficient at $500 \mathrm{~nm}$ of $0.0444 \mathrm{~m}^{-1}$, but did not report results for other wavelengths. Tyler and Smith (1970), however, give spectral extinction coefficients from 400 to $700 \mathrm{~nm}$ for various bodies of water.

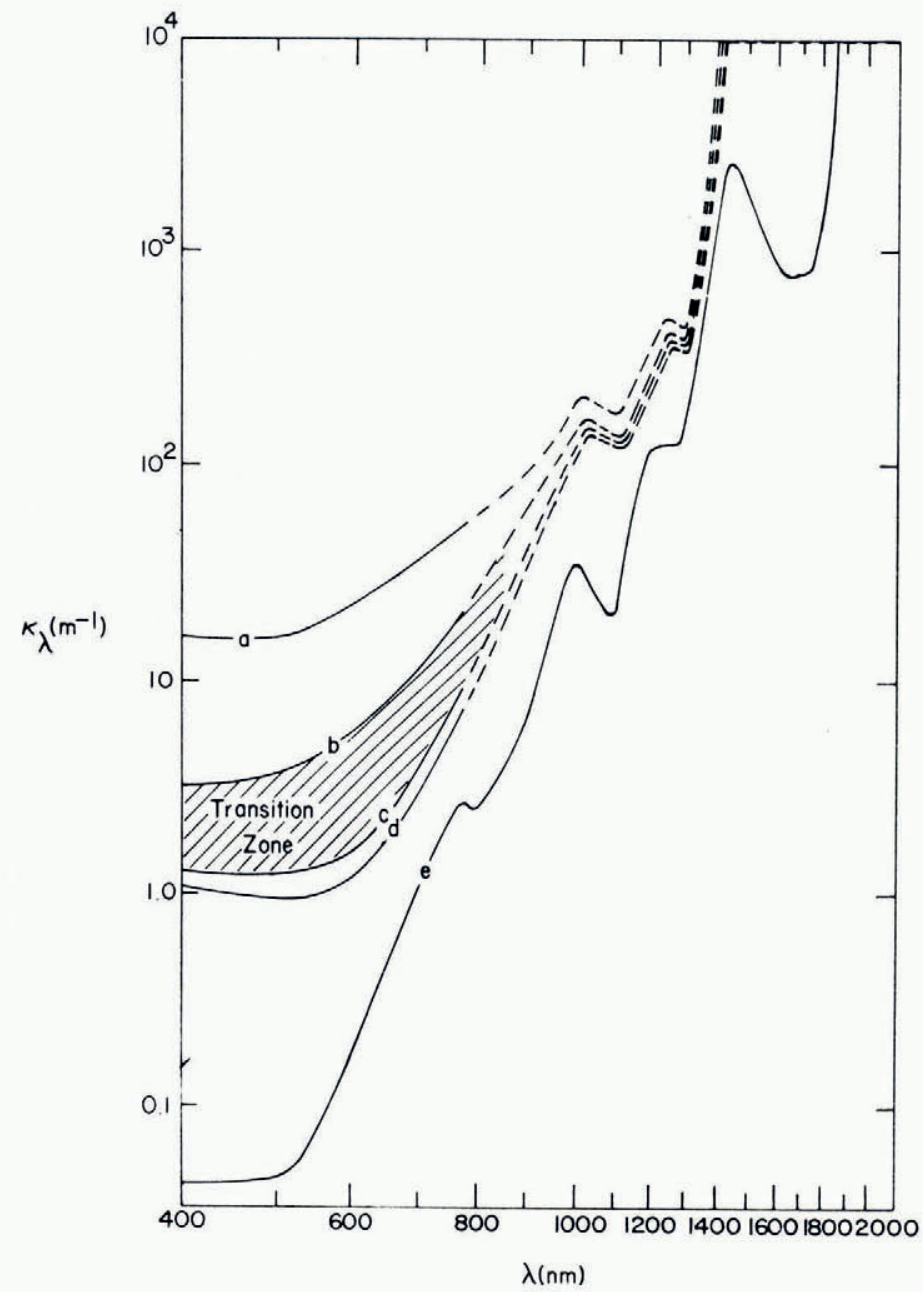

Fig. 2. Spectral extinction coefficients for (a) snow, (b) white ice, surface scaltering layer, (c) white ice, interior, (d) blue ice, and $(e)$ water. The hatched area between $(b)$ and $(c)$ represents the transition zone of white ice. Extrapolated calues are indicated by the dashed curve segments. 
Since their values for the Gulf Stream near $500 \mathrm{~nm}$ are consistent with those of Smith (1973) these results are assumed to apply to the polar oceans as well. At longer wavelengths, extinction coefficients are taken from Aschkinass (1895) since they closely match the values of Tyler and Smith near $700 \mathrm{~nm}$. Composite curves of the extinction coefficients from $400 \mathrm{~nm}$ to $2 \mathrm{I} 50 \mathrm{~nm}$ are given in Figure 2.

Volume reflectances for ice and snow are derived from spectral albedos and extinction coefficients using Equations ( I)-(3). Spectral albedos from 400 to $\mathrm{I}$ ooo $\mathrm{nm}$ are taken from Grenfell and Maykut. (1977). Beyond I ooo nm albedos appear to be available only for "old snow" (McClatchey and others, I97I); however, O'Brien and Munis (1975) have made extensive measurements of spectral reflectance relative to $\mathrm{BaSO}_{4}$ for different types of snow. In combination with the spectral reflectance of $\mathrm{BaSO}_{4}$ (Grum and Luckey, 1968), $\alpha_{\lambda}$ is estimated for dry snow out to 2 I $50 \mathrm{~m}$. For white ice $\alpha_{\lambda}$ is extrapolated smoothly down to he limit of specular reflection near I $300 \mathrm{~nm}$, while for blue ice $\alpha_{\lambda}$ reaches this limit just below $\mathrm{I}$ ooo $\mathrm{nm}$ and extrapolation is not required. In the ocean $r_{\lambda}{ }^{w}$ is assumed to be zero at all

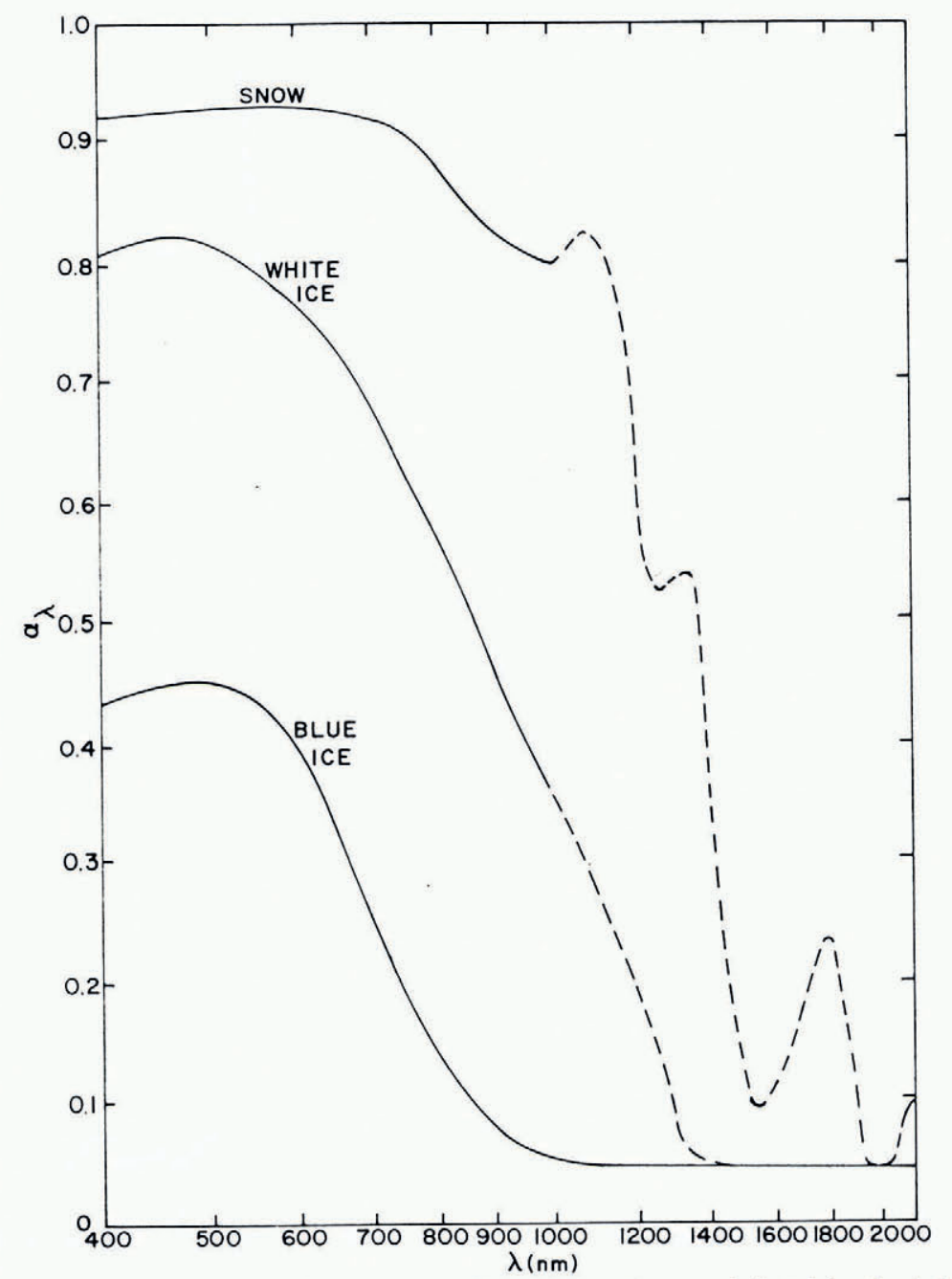

Fig. 3. Spectral albedos for blue ice, white ice, and snow. Extrapolated values are indicated by the dashed curve segments. 
wavelengths. Spectral albedos adopted for optically thick layers of snow, ice, and water are shown in Figure 3 .

Specular reflection for all surface types is assumed to be 0.05 at $450 \mathrm{~nm}$ and is scaled with wavelength according to variations in the refractive index based on the formulation of Alkezweeny and Hobbs (1966). $R_{\lambda}$ decreases slowly with increasing wavelength reaching a value of about 0.045 near 2 i $50 \mathrm{~nm}$.

Determination of actual irradiance levels and energy absorption rates in the ice and ocean requires absolute values of incident spectral irradiance. Both the magnitude and spectral composition of $F_{0}(\lambda)$ are significantly affected by variations in cloudiness as a result of backscattering and selective absorption in the infrared due to cloud particles and water vapor. To show the effects of a continuous cloud cover, incident irradiances are required for conditions of clear skies and heavy overcast. Illumination is chosen to be representative of late spring and summer conditions in the Arctic.

For clear skies $F_{0}(\lambda)$ is taken from Gast (1960) assuming a solar zenith angle of $60^{\circ}$ (air mass of 2). In this case more than $99^{\circ} \%$ of the energy falls between $400 \mathrm{~nm}$ and $2150 \mathrm{~nm}$. For cloudy skies, spectral data are scarce; however, crude measurements have been reported for both clear and cloudy conditions at mid-latitudes by Sauberer and Dirmhirn (1958). In the Arctic, a typical cloud cover reduces the total incident irradiance $F_{0}$ by only a factor of two to three (Vowinckel and Orvig, I962; Weaver, 1970) as opposed to a factor of ten more typical for heavy overcast at lower latitudes. Consequently, $F_{0}(\lambda)$ for cloudy skies is determined from the data of Gast ( 1960 ) using the relative spectral values from Sauberer and

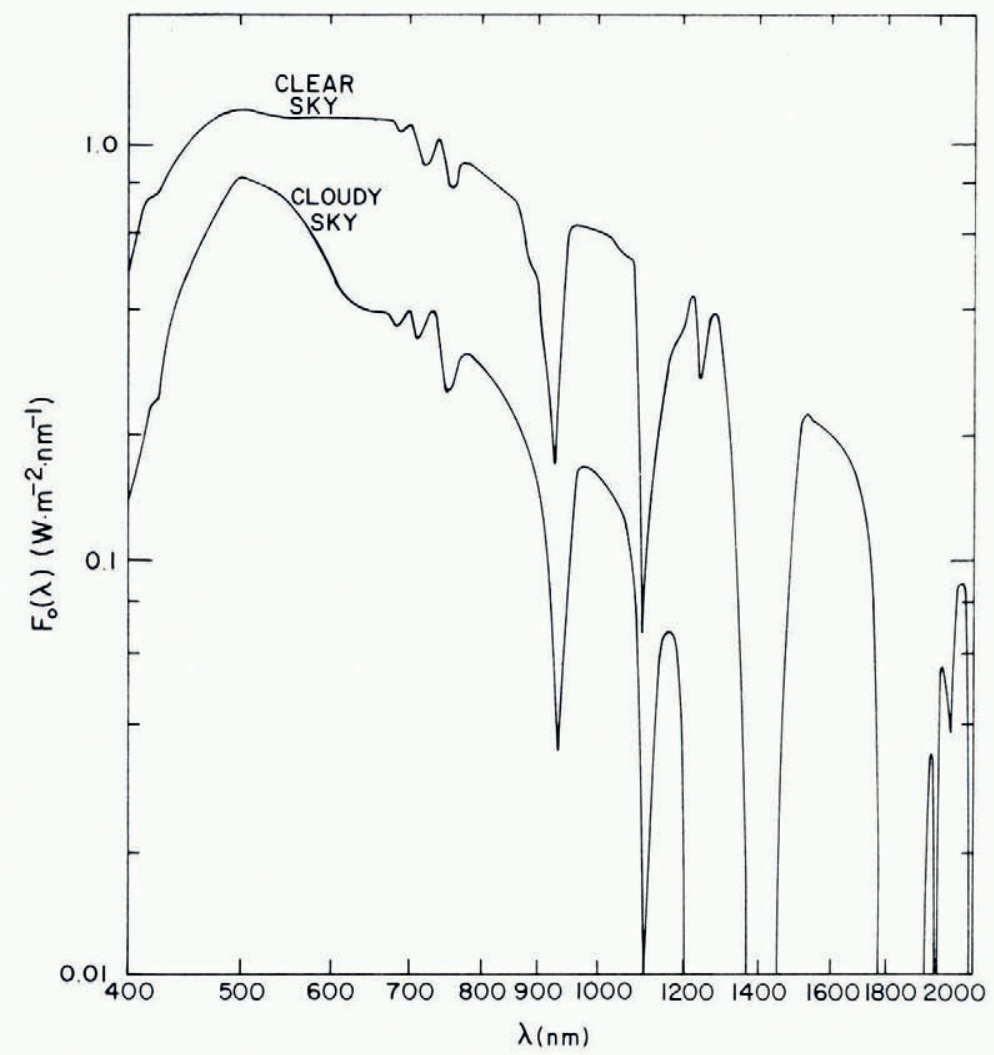

Fïg. 4. Solar spectrum for clear and cloudy skies from $400 \mathrm{~mm}$ to $2150 \mathrm{~mm}$. 
Dirmhirn (1958), but the reduction in total incident irradiance is assumed to be a factor of three. In this case almost none of the incident radiation lies beyond $1200 \mathrm{~nm}$ due to the large attenuation by water vapor at infrared wavelengths. The curves of $F_{0}(\lambda)$ used here are given in Figure 4 .

\section{Results}

The radiative model has been chosen to apply specifically to the polar regions during the spring and summer. In this period the solar elevation changes slowly, and the major variations in $F_{0}(\lambda)$ are due to clouds. The radiation field in the ice and snow was calculated at 45 wavelengths covering the solar spectrum, and ice thicknesses of $0.02,0.05,0.1,0.2,0.4$, and $0.8 \mathrm{~m}$ were studied. For blue ice, overlying snow layers of $0.01,0.02,0.05,0.1,0.2$, and $0.4 \mathrm{~m}$ were also included. Comparative results for Beer's law were determined by assuming an ice thickness of $10 \mathrm{~m}$ and calculating irradiances in the upper $0.8 \mathrm{~m}$. Wavelength-integrated irradiances were then calculated numerically in order to find total albedos and transmitted energies. Energy absorption (Equation (4)) was also evaluated numerically using a threepoint Lagrange differentiation formula (Davis and Polonsky, 1964).

Since the extinction coefficients of white ice vary through the transition zone, a differential method was employed to find net irradiances. The spectral albedo and $F_{\text {net }}(o, \lambda)$ were calculated first using depth-averaged optical properties. A series of ratios $F_{\text {net }}(h, \lambda) /$ $F_{\text {net }}(h-\Delta h, \lambda)$, beginning at the surface, was then determined from the extinction coefficients for depth $h-\frac{1}{2} \Delta h$ from which the irradiance profile was constructed.

\section{Albedos}

In general the spectral albedos of ice and snow increase with total thickness at a rate which depends on depth. When the layer is optically thin $\left(\tau_{\lambda}<1\right), \alpha_{\lambda}$ is most sensitive to $h$. When the optical depth becomes large $\left(\tau_{\lambda} \geqslant 4\right)$, the up-welling irradiance originating near the bottom is absorbed before reaching the surface and $\alpha_{\lambda}$ is no longer influenced by changes in ice thickness. Because of the strong spectral dependence of $\kappa_{\lambda}$, the geometrical thickness for which $\tau_{\lambda}$ equals four is a function of wavelength. For example, at wavelengths beyond I ooo $\mathrm{nm}$ albedos do not change once the ice grows thicker than about $0.02 \mathrm{~m}$; however, at $500 \mathrm{~nm}$, where $\kappa_{\lambda}$ is a minimum, the albedo of an $0.8 \mathrm{~m}$ layer of blue ice has reached only $85^{\circ} \%$ of its maximum possible value.

The total albedo, given by $\alpha=\int \alpha_{\lambda} F_{0}(\lambda) \mathrm{d} \lambda / \int F_{0}(\lambda) \mathrm{d} \lambda$, combines the contribution of $\alpha_{\lambda}$ over the entire solar spectrum. As the first few centimeters of ice growth or snow deposition occur, the spectral albedos increase at all wavelengths and $\alpha$ rises rapidly. For thicker layers the increase of $\alpha$ slows as the ice or snow becomes optically thick over a growing wavelength range. Figure 5 shows the calculated dependence of $\alpha$ on layer thickness for blue ice, white ice, and snow. The total albedo reaches about $99.8 \%$ of its maximum value when $\tau_{500}=4$, corresponding to a geometrical thickness of $h^{\star}=4 / \kappa_{500}$. For snow $h^{\star}=0.25 \mathrm{~m}$, while for blue and white ice the values of $h^{\star}$ are $3.3 \mathrm{~m}$ and $1.1 \mathrm{~m}$ respectively.

Also shown in Figure 5 are the differences in the albedo for clear and cloudy skies. Because $\alpha_{\lambda}$ is weighted by the incident spectral irradiance, the removal of infrared radiation favors shorter wavelengths where $\alpha_{\lambda}$ is larger. Consequently, on cloudy days $\alpha$ increases by $13 \%$ for snow, $22 \%$ for white ice, and $30 \%$ for blue ice.

\section{Transmission}

The influence of the lower boundary is also apparent in the behavior of the net irradiance. To illustrate the behavior of the spectral irradiance in the ice, a representative series of profiles 


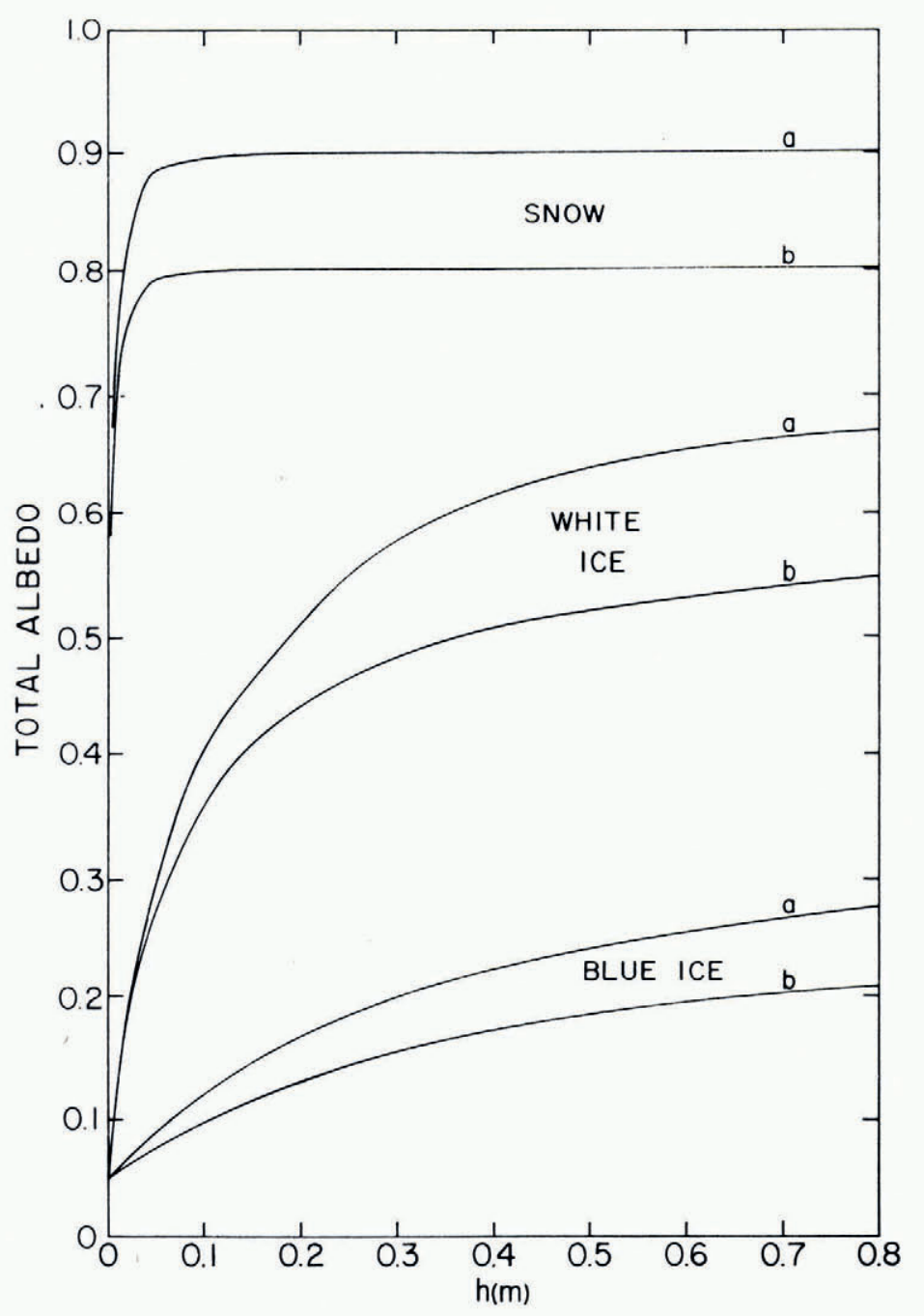

Fig. 5. Total albedo versus ice thickness for blue ice, white ice, and snow under (a) cloudy and (b) clear skies.

is shown in Figure 6 for blue ice under clear skies at $650 \mathrm{~nm}$. Ice thicknesses range from 0.05 to $0.8 \mathrm{~m}$. The Beer's law profile is also included. Since $F_{\text {net }}(h, \lambda)$ is proportional to $\left(\mathrm{I}-\alpha_{\lambda}\right)$, the curves for different ice thicknesses are displaced vertically in the sense that, at a given depth, $F_{\text {net }}(h, \lambda)$ is lower for thicker layers. If $\alpha_{\lambda}$ were constant, all of the curves would coincide at the upper surface. In addition, the depth dependence of the net irradiance depends on thickness. Because back-scattering in the water is assumed to be zero, it produces no contribution to the up-welling irradiance in the ice. Consequently, the up-welling irradiance at a given level comes only from the ice below that level and must drop to zero at the ice-water boundary. On the other hand, contributions to the down-welling irradiance from below arise from radiation which has undergone multiple back-scattering and are quite small, so the down-welling irradiance is only slightly affected by the location of the lower boundary. The resulting net irradiance then decreases less rapidly than Beer's law predicts. 
For 0.2 to $0.8 \mathrm{~m}$ ice $F_{\text {net }}(h, \lambda)$ shows a marked upward curvature away from an exponential behavior. The insert to Figure 6 gives the individual up- and down-welling components for $0.8 \mathrm{~m}$ ice together with the corresponding net irradiance. At other wavelengths the behavior of the profiles is similar.

At $650 \mathrm{~nm}$ the model predicts a transmitted irradiance for $0.05 \mathrm{~m}$ blue ice of 1.42 times as large as does Beer's law. This excess decreases to about $\mathrm{r} .34$ for $0.8 \mathrm{~m}$ ice, and it approaches a lower limit, $\mathscr{L}_{650}$, of ${ }_{1} \cdot 30$ for optically thick layers. $\mathscr{L}_{\lambda}$ is obtained from the ratio of the transmitted net irradiance to the transmission predicted by Beer's law in the limit of very large total thickness. Specifically

$$
\mathscr{L}_{\lambda}=2 \sinh \gamma /[\exp \gamma-\mathrm{I}] .
$$

$\mathscr{L}_{\lambda}$ is largest $(\mathrm{I} .43)$ at about $500 \mathrm{~nm}$ where scattering is most important relative to absorption ( $\gamma$ is a minimum), and it decreases to $\mathrm{I}$ at longer wavelengths where absorption dominates

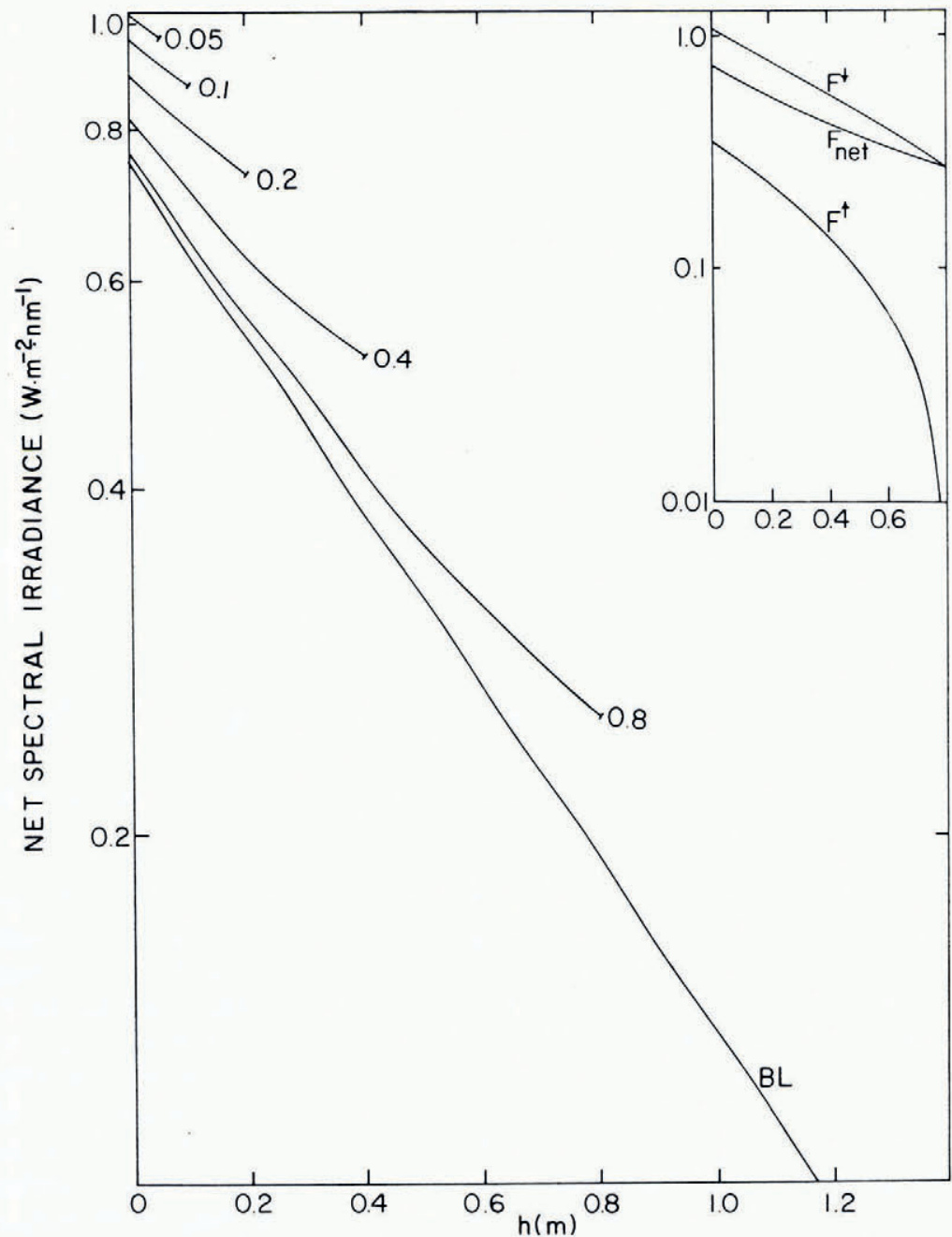

Fig. 6. Net spectral irradiance at $6_{50} \mathrm{~nm}$ versus depth for blue ice as a function of ice thickness. The insert shows up- and down-welling components together with resulting $F_{\text {net }}(h)$ for $0.8 \mathrm{~m}$ blue ice. 
$(\gamma \gg \mathrm{I})$. For white ice and snow, $\mathscr{L}_{500}$ is I.86 and 1.97 respectively, closely approaching the limit of 2 for pure scattering $(\gamma \rightarrow 0)$.

The depth dependence of the wavelength-integrated net irradiance $F_{\text {net }}(h)$ in the ice and underlying ocean is characterized by a rapid drop in the first 0.02 to $0.05 \mathrm{~m}$, where most of the infrared is absorbed, followed by a more gradual decrease deeper in the ice. At the bottom of the ice $F_{\text {net }}(h)$ experiences a discontinuity in slope due to the difference between the optical properties of ice and water. In water the irradiance obeys Beer's law, that is, the spectral irradiance profiles are exponential at all wavelengths. Representative curves of $F_{\text {net }}(h)$ are shown in Figure 7 for homogeneous blue ice under both clear and cloudy skies. The circles show $F_{\text {net }}(0)$, and the ice-water boundary is indicated by the diamonds. On clear days $F_{\text {net }}(\mathrm{o})$ is about three times as large as on cloudy days, however, the decrease in the first $0.02 \mathrm{~m}$ is more than twice as great because of the larger percentage of the incident radiation in the infrared.

Since the integrated net irradiance $F_{\text {net }}(h)$ combines the results at individual wavelengths, values of net irradiance at any depth are larger for thinner ice. Also each of the integrated

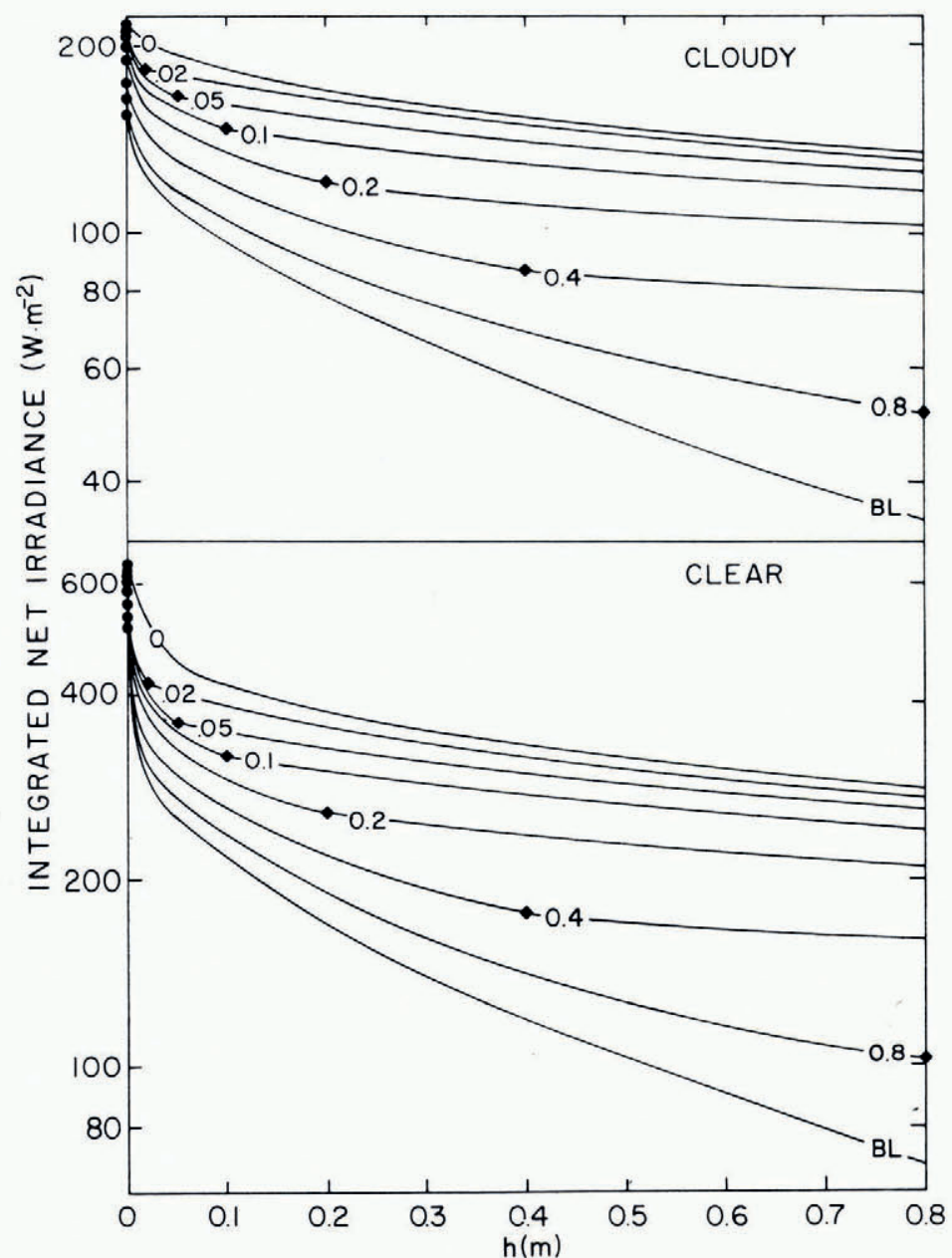

Fig. 7. Integrated net irradiance versus depth for blue ice as a function of ice thickness under clear and cloudy conditions. The circles indicate $F_{\text {net }}(o)$ and the diamonds show the location of the ice-water boundarv. 
profiles curves upward away from Beer's law with increasing depth. Calculations for white ice and snow show similar results; however, the individual profiles are, in general, more widely separated due to the larger albedo variations, and there is a stronger decrease in the first $0.05 \mathrm{~m}$. The excess energy transmission relative to Beer's law by blue ice is about 1.5 for all cases presented in Figure 7 because reductions in $F_{\text {net }}(h)$ resulting from the increase of albedo with ice thickness are just compensated by changes in the shape of the profiles. This does not hold for white ice, on the other hand, and the excess transmission ranges from 1.9 for $0.8 \mathrm{~m}$ ice to 3.0 for $0.02 \mathrm{~m}$ ice. Since these results are expressed as ratios of total transmission predicted for the same illumination conditions by the two models, the effects of cloudiness tend to cancel, and the excess transmission is nearly independent of the cloud cover.

Reduction in the incident irradiance by clouds does not affect the transmitted irradiances as strongly. Because the ice quickly absorbs most of the incident infrared radiation, transmission above $800 \mathrm{~nm}$ is small even on clear days. As a result, with the present assumption that the total incident irradiance is reduced threefold by a cloud cover, the amount of radiation transmitted by blue ice drops by only a factor of 2 to 2.5 for 0.8 and $0.02 \mathrm{~m}$ ice respectively. Analogous calculations performed for white ice show that the behavior of $F_{\text {net }}\left(h_{\mathbf{i}}\right)$ is qualitatively similar to that of blue ice, but since infrared absorption is even stronger the reduction in transmission is only 1.9 for $0.8 \mathrm{~m}$ ice and 2.2 for $0.02 \mathrm{~m}$ ice.

\section{Energy absorption}

In general, the energy absorption, given by Equation (4), is greatest at the surface, dropping off rapidly in the first 0.05 to $0.1 \mathrm{~m}$ as the infrared radiation is removed, then decreasing more gradually below $0.1 \mathrm{~m}$ as the remaining radiation is attenuated. Comparative calculations for thick blue and white ice (Fig. 8) show that, although energy absorption at the surface is greater for white ice, it falls below the value for blue ice at about $5 \mathrm{~mm}$. This is mainly due to the high extinction in the surface layer of white ice, which lowers the transmission to the interior. Much more radiation penetrates deep into blue ice, since it has no surface scattering layer; therefore, because absorption depends on the irradiance level as well as $\kappa_{\lambda}$, energy input to the interior of blue ice is larger even though the extinction coefficients are smaller.

Calculations performed for clear skies show that the energy absorption curves are similar in relative magnitude to those for the cloudy case. Below o. $1 \mathrm{~m}$ in both blue and white ice, however, total absorption is about twice as large as on cloudy days. Near the surface, the absorption is about 50 times greater under clear skies because of the larger percentage of infrared in $F_{0}$ in addition to the higher irradiance levels.

Energy absorption has also been determined for the thin-ice cases, but, because the curves overlap near the surface, they are not included in Figure 8. Instead, the ratio of energy absorption relative to that of Beer's law is determined. Results are shown in Figure 9 for both blue and white ice under cloudy conditions. At the surface the divergence is the same as for Beer's law to within $0.2 \%$ for either ice type, because the energy is absorbed predominantly at wavelengths greater than $\mathrm{I}$ ooo $\mathrm{nm}$. In this spectral region extinction coefficients are so large that the influence of the lower boundary is negligible.

Since the effect of the lower boundary condition is to slow the rate at which $F_{\text {net }}(h)$ decreases with depth, the resulting energy absorption tends to fall below the Beer's law prediction. This effect is stronger for thinner ice so that in homogeneous blue ice the absorption at a given depth is lowest for the $0.02 \mathrm{~m}$ case and increases with ice thickness, reaching a maximum for the Beer's law case.

The same effect is present for white ice; however, it is dominant only below the surface scattering layer or near the lower boundary. In the surface layers more energy can be absorbed than Beer's law predicts because the rapid increase of $\alpha$ with ice thickness results in a 


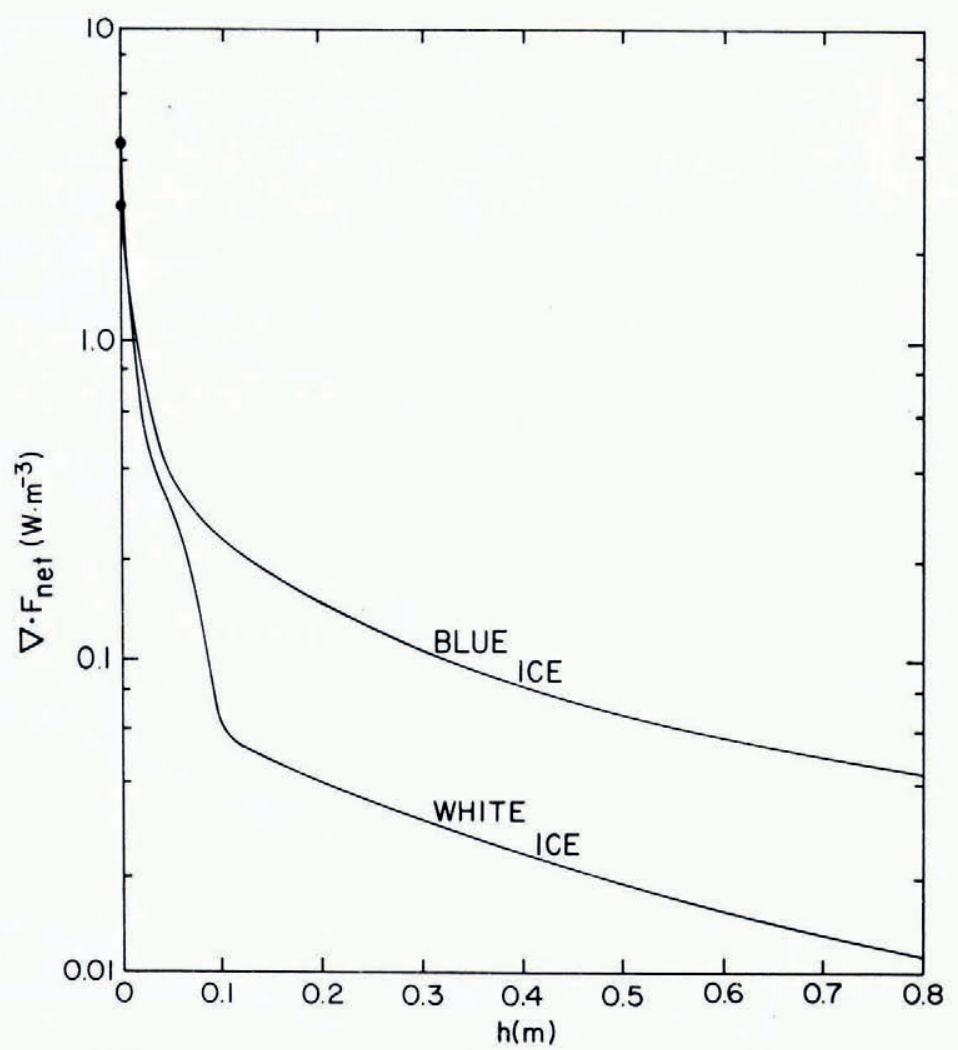

Fig. 8. Divergence of the net irradiance $\left(\nabla \cdot F_{\text {net }}\right)$ versus depth in thick $(10 \mathrm{~m})$ blue and white ice. Cloudy conditions.

strong decrease in net irradiance. For Beer's law, the irradiance near the surface is low enough that its depth derivative is smaller than for thin ice. The relative absorption curves for white ice then start at $\mathrm{I}$ for $h=\mathrm{O}$ and rise to a maximum as the influence of the lower boundary condition increases. At greater depths the curves drop below I and decrease smoothly to the bottom of the ice. The maximum occurs closer to the surface for thinner ice because of the stronger influence of the lower boundary. In the $0.02 \mathrm{~m}$ case the lower-boundary effect is dominant and the relative absorption in the ice never rises above unity.

In the water below the discontinuity the relative absorption rises gradually even though $\kappa_{\lambda}{ }^{\mathrm{w}}$ is smaller than $\kappa_{\lambda}{ }^{\mathrm{i}}$ because the irradiance levels in the infinite ice layer are much lower than those in the water. Ultimately all the curves rise above unity. For blue ice this occurs deepest-at $\mathrm{r} .3 \mathrm{~m}$ beneath $0.02 \mathrm{~m}$ ice and at about $4 \mathrm{~m}$ beneath $0.8 \mathrm{~m}$ ice. The low relative absorption in the uppermost $20 \mathrm{~mm}$ of open water is a result of the lower infrared extinction coefficients.

\section{Discussion}

For practical application of the present results to more general problems of the total energy balance of sea ice, it is desirable to approximate the behavior of the radiation field in a compact parameterized form. In the approach of Grenfell and Maykut (1977), a simple Beer's law formulation is used for sea ice by including a surface transmission term $i_{0}$ to account for infrared absorption in the upper 0.1 to $0.2 \mathrm{~m}$ of the ice. Although the choice of $i_{0}$ depends 


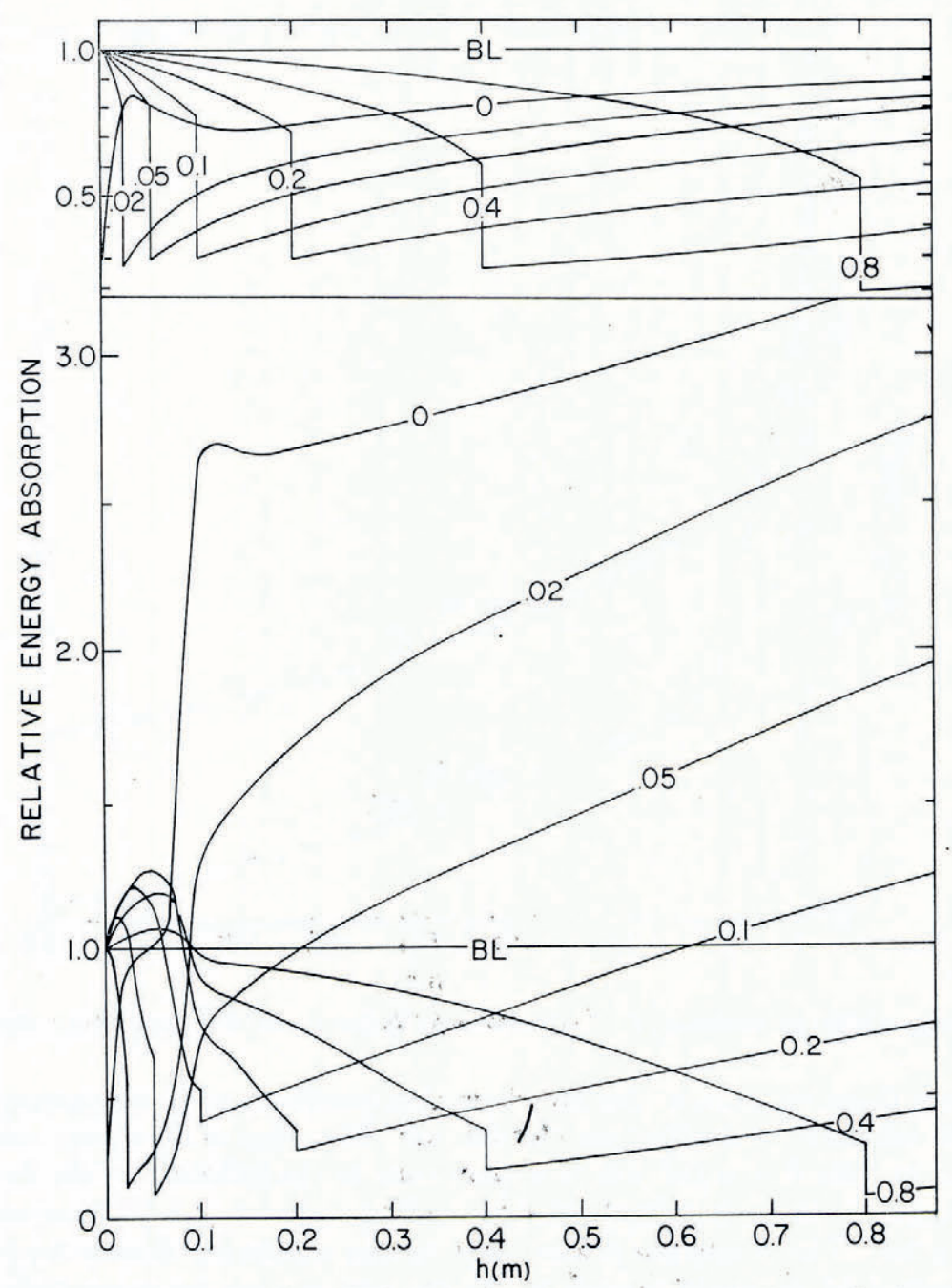

Fig. 9. Energy absorption relative to Beer' law $\left[\left(\nabla \cdot F_{\text {net }}\right)_{h_{1}} /\left(\nabla \cdot F_{\text {net }}\right)_{\mathrm{BL}}\right]$ versus depth as a function of ice thickness for blue ice (top) and white ice (bottom). Cloudy conditions.

on ice type and cloud conditions, a single bulk extinction coefficient can be used. To extend the formulation to thin ice, $i_{0}$ is defined as the fraction of $F_{\text {net }}(h)$ transmitted through the entire ice layer, since Beer's law is a poor approximation for $h_{1} \leqslant 0.8 \mathrm{~m}$. Hence the amount of radiative energy absorbed by the ice is $E_{\mathrm{a}}=F_{\mathrm{o}}(\mathrm{I}-\alpha)\left(\mathrm{I}-i_{\mathrm{o}}\right)$, and the energy transmitted to the ocean is $E_{\mathrm{t}}=F_{0}(\mathrm{I}-\alpha) i_{0}$. As a first approximation it can be assumed that all the energy absorbed by the ice contributes to surface melting, so that $\alpha$ and $i_{0}$ alone are sufficient to specify the radiative energy balance at the surface. Consequently $\alpha$ and $i_{0}$ have been parameterized as functions of ice thickness for each surface type under clear and cloudy skies. Equations for snow-covered blue ice are given separately to avoid inaccuracies due to the strong albedo variations which occur for small changes in thin (less than ro $\mathrm{mm}$ ) snow layers.

Formulae for $\alpha$ and $i_{0}$ are presented in Tables I and II respectively for ice thicknesses between 0.02 and $0.8 \mathrm{~m}$ and for 0.01 to $0.4 \mathrm{~m}$ layers of snow. Although snow albedos are 
actually calculated for snow-covered blue ice, variations in thickness of the underlying ice layer have a negligible effect for more than $10 \mathrm{~mm}$ of snow. Thus, the albedo is due to the snow layer alone and the dependence on $h_{\mathrm{i}}$ can be suppressed. This is not true for $i_{0}$, however, and two-dimensional representation is required for snow-covered ice. The quoted errors are maximum deviations between the parameterization formulae and the model results.

\begin{tabular}{|c|c|c|c|c|c|c|}
\hline Ice type & Cloudiness & $A$ & $B$ & $C$ & $D$ & Error \\
\hline Blue ice & Clear & 0.130 & $15 \cdot 4^{6}$ & 0.820 & 0.1216 & $<\mathrm{I}_{0}^{0}$ \\
\hline $0.8 \mathrm{~m} \geqslant h_{\mathrm{i}} \geqslant 0.02 \mathrm{~m}$ & Cloudy & 0.150 & 12.02 & 0.800 & 0.2161 & $<1^{\circ} \%$ \\
\hline White ice & Clear & $0.4^{19}$ & 12.40 & 0.531 & o.1958 & $<2.5^{\circ}$ \\
\hline $0.8 \mathrm{~m} \geqslant h_{\mathrm{i}} \geqslant 0.02 \mathrm{~m}$ & Cloudy & 0.540 & 10.11 & 0.410 & 0.2827 & $<3 \%$ \\
\hline Dry packed snow over blue ice & Clear & 0.2213 & $77.4^{8}$ & o. 198 & o & $<5 \%$ \\
\hline $0.4 \mathrm{~m} \Rightarrow h_{\mathrm{s}}>0.01 \mathrm{~m}$ & Cloudy & 0.3181 & $77.8_{1}$ & 0.100 & 0.05076 & $<7^{\circ} \circ$ \\
\hline
\end{tabular}

TABLE II. $i_{0}$ PARAMETERIZATION

\begin{tabular}{|c|c|c|c|c|c|c|}
\hline Ice type & Cloudiness & $A$ & $B$ & $C$ & $D$ & Error \\
\hline Blue ice & Clear & o. $19^{2} 5$ & 12.96 & $0.5^{1} 5$ & I.227 & $<4^{\circ}$ n \\
\hline $0.8 \mathrm{~m} \geqslant h_{\mathrm{i}} \geqslant 0.02 \mathrm{~m}$ & Cloudy & 0.1553 & 12.84 & 0.755 & 1.081 & $<2 \%$ \\
\hline White ice & Clear & $0.3^{89} 4$ & 12.39 & $0.35^{\circ}$ & 1.578 & $<4 \%$ \\
\hline $0.8 \mathrm{~m} \geqslant h_{\mathrm{i}} \geqslant 0.02 \mathrm{~m}$ & Cloudy & 0.3456 & 10.30 & 0.590 & 1.315 & $<2.5 \%$ \\
\hline $\begin{array}{l}\text { Dry packed snow over blue ice } \\
0.4 \mathrm{~m} \geqslant h_{\mathrm{s}} \geqslant 0.01 \mathrm{~m} \\
0.8 \mathrm{~m} \geqslant h_{\mathrm{i}} \geqslant 0.01 \mathrm{~m}\end{array}$ & Clear & \multicolumn{5}{|c|}{$\begin{aligned} A & =0.2257 \exp \left(-16.73 h_{\mathrm{s}}\right) 0.4174 \exp \left(-43.89 h_{\mathrm{s}}\right) \\
B & =0.7280 \exp \left(-0.1862 h_{\mathrm{s}}\right)+0.3532 \exp \left(-13.04 h_{\mathrm{s}}\right) \\
C & =0.156 \mathrm{I} \exp \left(-92.79 h_{\mathrm{s}}\right) \\
D & =\left[0.06-0.0995 \exp \left(-94.20 h_{\mathrm{s}}\right)\right]^{-1}\end{aligned}$} \\
\hline . & Cloudy & $\begin{array}{l}A=0.980 \\
B=0.6945 \\
C=D=0\end{array}$ & $\begin{array}{r}-17.81 h \\
(-0.104\end{array}$ & (1) & $54 \cdot 9^{2} h_{\mathrm{s}}{ }^{1}$ & $<6^{\circ}$ o \\
\hline
\end{tabular}

\section{Conclusions}

As a basis for predicting the radiative energy absorbed and transmitted by young sea ice, it is important to use a wavelength-dependent analysis with a model which accounts for the finite thickness of the ice. The two-stream model used here is the simplest theory which fulfills these requirements. It has an analytic solution which allows for rapid calculations over a large wavelength set while retaining the essential physics. It shows that energy absorption near the surface is sensitive both to spectral albedos in the I 000 to $3000 \mathrm{~nm}$ range and to the effects of cloudiness on the incident spectral irradiance. According to the two-stream model up to $200 \%$ more energy is transmitted by thin ice than is predicted by Beer's law. Although a more complex model treating the angular distribution of the radiation field would presumably provide greater accuracy, its use is not yet feasible due to the lack of scattering functions for sea ice. Such a model would be most valuable for interpreting remote-sensing data from satellites and for calculating the energy balance during cloud-free periods when the incident radiation field is highly anisotropic.

An important goal of the present work is to provide a simple method for determining the rate of energy absorption and transmission using parameterizations of $\alpha$ and $i_{0}$. The radiative energy balance can then be obtained from total incident irradiances routinely measured with thermopile radiometers in most field investigations. The principal uncertainties involved are the shape of the solar spectrum on cloudy days, the optical properties of young growing ice, and the lack of spectral albedos beyond I $000 \mathrm{~nm}$. It is difficult, however, to estimate the magnitude of errors thus introduced, and although considerable effort has been made to maintain consistency with available data, additional field measurements are necessary to refine the present results. 


\section{Acknowledgements}

My sincere thanks go to Dr Gary Maykut for many helpful suggestions in preparing this manuscript. This work was made possible by continued support from the Office of Naval Research, Arctic Program, under Contract Nooor4-76-C-0234.

MS. received II April 1978 and in revised form 20 July 1978

\section{REFERENCES}

Alkezweeny, A. J., and Hobbs, P. V. 1966. The reflection spectrum of ice in the near infrared. Journal of Geophysical Research, Vol. 71 , No. 4, p. $1083-86$.

Aschkinass, E. 1895 . Ueber das Absorptionsspectrum des flüssigen Wassers. Annalen der Physik und Chemie, Neue Folge, Bd. 55 , Ht. 7 , p. 401-31.

Bohren, C. F., and Barkstrom, B. R. 1974. Theory of the optical properties of snow. Journal of Geophysical Research, Vol. 79 , No. 30 , p. $4527-35$.

Davis, P. J., and Polonsky, I. I964. Numerical interpolation, differentiation, and integration. (In Abramowitz, M., and Stegun, L. A., ed. Handbook of mathematical functions. Washington, D.C., U.S. Government Printing Office, p. 882-83.)

Dunkle, R. V., and Bevans, J. T. 1956. An approximate analysis of the solar reflectance and transmittance of a snow cover. Fournal of Meteorology, Vol. 13 , No. 2, p. 212-16.

Ewan, T. 1895. On the absorption spectra of dilute solutions. Proceedings of the Royal Society of London, Vol. 57, No. 341 , p. $117-61$.

Gast, P. R. I 960 . Solar radiation. (In Campen, C. F., and others, ed. Handbook of geophysics. Edited by C. F. Campen [and 5 others]. New York, Macmillan, p. 16-14-16-32.)

Grenfell, T. C., and Maykut, G. A. 1977. The optical properties of ice and snow in the Arctic Basin. Journal of Glaciology, Vol. 18, No. 8o, p. $445-63$.

Grum, F., and Luckey, G. W. 1968. Optical sphere paint and a working standard of reflectance. Applied Optics, Vol. 7 , No. 11 , p. 2289-94.

Liljequist, G. H. 1956. Energy exchange of an Antarctic snow-field. Short-wave radiation (Maudheim, $71^{\circ} 03^{\prime} \mathrm{S}$. , $10^{\circ} 6^{\prime}$ W.). Norwegian-British-Swedish Antarctic Expedition, 1949-52. Scientific Results, Vol. 2, Pt. IA.

McClatchey, R. A., and others. 1971. Optical properties of the atmosphere, by R. A. McClatchey [and 4 others]. U.S. Air Force. Cambridge Research Laboratories. Environmental Research Paper No. 354.

O'Brien, H. W., and Munis, R. H. 1975. Red and infrared spectral reflectances of snow. U.S. Cold Regions Research and Engineering Laboratory. Research Report 332.

Ockman, N. 1958. The infra-red and Raman spectra of ice. Advances in Physics, Vol. 7, No. 26, p. 199-220.

Sauberer, F. 1938. Versuche über spektrale Messungen der Strahlungseigenschaften von Schnee und Eis mit Photoelementen. Meteorologische Zeitschrift, Bd. 55, Ht. 7, p. $250-55$.

Sauberer, F., and Dirmhirn, I. 1958. Das Strahlungsklima. (In Steinhauser, F., and others, ed. Klimatographie von Österreich. Hrsg. und bearbeitet von F. Steinhauser, O. Eckel, F. Lauscher. Osterreichische Akademie der Wissenschaften. Denkschriften der Gesamtakademie, Bd. 3, I. Lief., p. 13-102.)

Schúster, A. 1905. Radiation through a foggy atmosphere. Astrophysical Journal, Vol. 21, No. 1, p. I-22.

Smith, R. C. 1973. Optical properties of the Arctic upper water. Arctic, Vol. 26, No. 4, p. 303-13.

Tyler, J. E., and Smith, R. C. 1970. Measurements of spectral irradiance underwater. New York, etc., Gordon and

Breach.
Vowinckel, E., and Orvig, S. 1962. Relation between solar radiation income and cloud type in the Arctic. Arctic Meteorology Research Group, McGill University. Publication in Meteorology No. 48.

Weaver, D. F. 1970. Radiation regime over Arctic tundra and lake, 1966. [Seattle], Dept. of Atmospheric Sciences, University of Washington. (U.S. Office of Naval Research. Contract Nooo14-67-A-0103-0007. Project No. 307-252, Scientific Report No. 6.) 